\title{
Vermicompost for Indigo Blue and Congo Red Removal
}

\author{
Joselito Nardy Ribeiro ${ }^{1}$, Araceli Veronica F. N. Ribeiro², Andre Romero da Silva ${ }^{3}$, \\ Madson de Godoi Pereira ${ }^{4}$, Jairo Pinto de Oliveira1, Alveriana Tagarro Tomaz ${ }^{2}$, Barbara Vitoria ${ }^{2}$
}

\author{
${ }^{1}$ Health Science Center, Federal University of Espirito Santo, Vitoria-ES, Brazil \\ ${ }^{2}$ Federal Institute of Espirito Santo, Vila Velha-ES, Brazil \\ ${ }^{3}$ Federal Institute of Espirito Santo, Aracruz-ES, Brazil \\ ${ }^{4}$ Department of Exact and Earth Sciences, University of Bahia State, Salvador-BA, Brazil \\ Email: ^rinajokrauser@gmail.com
}

How to cite this paper: Ribeiro, J.N., Ribeiro, A.V.F.N., da Silva, A.R., de Godoi Pereira, M., de Oliveira, J.P., Tomaz, A.T. and Vitoria, B. (2021) Vermicompost for Indigo Blue and Congo Red Removal. Journal of Water Resource and Protection, 13, 419-434.

https://doi.org/10.4236/jwarp.2021.136025

Received: May 2, 2021

Accepted: June 12, 2021

Published: June 15, 2021

Copyright $\odot 2021$ by author(s) and Scientific Research Publishing Inc. This work is licensed under the Creative Commons Attribution International License (CC BY 4.0).

http://creativecommons.org/licenses/by/4.0/

\begin{abstract}
The data obtained through this work revealed that the vermicompost is a natural adsorbent able to removal two textile dyes from an aqueous medium. The values of maximum adsorption capacity for congo red $(23.25 \mathrm{mg} / \mathrm{g})$ and indigo blue $(40.39 \mathrm{mg} / \mathrm{g}$ ) obtained from the Mathematical Langmuir Model reveal it. The conditions of adsorbent mass, stirring time between adsorbent and dyes were optimized. Additionally, the values of Gibbs free energy demonstrate the predominance of physical interaction between both dyes and vermicompost. Through Langmuir constant values, it was possible to identify similar affinities between both dyes and vermicompost. The value of dimensionless constant indicates favorable adsorptions process. Finally, through physicochemical analysis from scanning electron microscopy and Fourier Transform Infra-Red Spectroscopy, the characteristics of vermicompost were verified revealing essential aspects to efficient adsorbent.
\end{abstract}

\section{Keywords}

Vermicompost, Adsorption, Congo Red, Indigo Blue

\section{Introduction}

The adsorption of toxic dyes pollutants using natural adsorbents is widely studied [1]. For example, Kebaili et al. [2] studied orange industry residues as an adsorbent for methylene blue. Sun et al. [3] evaluated the use of Angelicae dahuricae residue for the adsorption of methylene blue. Ribeiro, A. et al. [4] evaluated the liquorice Glycyrrhiza glabra L. root powder for the removal of congo red and 
indigo blue in the water. Munagapati et al. [5] investigated the removal of reactive black 5 and congo red using banana peel. Raymundo et al. [6] evaluated sugar-cane bagasse as an adsorbent in the textile wastewater treatment contaminated with congo red dye. Wang et al. [7] utilized a green composite hydrogel based on cellulose and clay as an efficient absorbent of colored organic effluent. The optimized cellulose/montmorillonite hydrogels showed excellent methylene blue adsorption. Kubra et al. [8] showed that a polymeric natural carbohydrate was able to removal methylene blue dye from an aqueous medium. Jawad and Abduhameed [9] revealed the mesoporous Iraqi red kaolin clay as an efficient adsorbent for methylene blue dye. Pereira et al. [10] evaluated the vermicompost for organic cationic dyes retention. The results obtained by these authors were satisfactory for removal of crystal violet and methylene blue. Cygeroglu and Yildirir [11] evaluated the vermicompost to removal of methylene blue from aqueous medium obtaining excellent results. This same material was used in the bleaching of water containing other polluting dyes [12]. The vermicompost can be also used for the retention of other pollutants such as pesticides [13], metals ions [14], and pharmaceuticals [15]. The vermicompost has a complex physical and chemical structure and its production occurs in the digestive system of certain species of earthworms which feed on organic residues present in the soil. In the digestive system of these earthworms occurs the fragmentation of several biomolecules such as proteins and nucleic acids generating complex molecules rich in aromatic rings, carboxyl groups, and others which consequently returns to the soil and is denominated vermicompost [16]. In this work we studied the ability of vermicompost (VMC) to remove textile dyes present in aqueous medium. The dyes used were Congo Red (CR) and Indigo Blue (IB). Effluents of the industrial textile dye containing IB and its derivative anthranilic acid are hazardous to the aquatic environment [17] and CR is a toxic dye that has carcinogenic properties [18]. For this study, physicochemical tests were performed using Scanning Electron Microscopy (SEM) and Fourier Transform Infra-Red Spectroscopy (FTIR) to verify the vermicompost characteristics. Subsequently, the following parameters were evaluated: 1) mechanical agitation time between dye and adsorbent, 2) influence of adsorbent mass and dye concentration on the adsorptive process. Finally, the maximum adsorptive capacity (MAC) of vermicompost for Indigo Blue and Congo Red were calculated using the Langmuir mathematical model [10]. These experiments aimed to reveal the efficiency of vermicompost as a removing agent for CR and IB in aqueous media.

\section{Material and Methods}

\subsection{Materials}

Vermicompost was obtained from Suzan Humus (Suzano-SP, Brazil), congo red dye (CR) was purchased from Vetec Company (Duque de Caxias-RJ, Brazil), while Indigo Blue (IB) was purchased from Tupy Industry (São Paulo-SP, Brazil). Ultrapure water used to prepare all solutions was obtained from a water pu- 
rification unit Quimis (Q241-22 model, Diadema-SP, Brazil). Several laboratory glasswares were used, including beckers, erlemeyers, kitassato, and volumetric flasks. Others equipments were used such as: laboratory oven (Quimis Q-317 B model, Brazil), particle size sieves (Granutest, Brazil), Analytical balance (Shimadzu AY 220 model, Japan), sputter coater (Shimadzu, IC-50 Ion Coater model, Japan), scanning electron microscope (Shimadzu, SSX 550 model, Japan), infrared spectrophotometer (Cary 630 model, Agilent Technologies, Santa Clara, California, USA), pHmeter (PHTEK, Labitec, Londrina-PR, Brazil), magnetic stirrer (Warmnest, 78HW-1 model, Brazil), UV/Vis spectrophotometer (Even, IL-562 model, Brazil). For data processing, a graphical/statistical program Origin version 6.1 was used (OriginLab Corporation, Northampton, MA 01060, United States).

\subsection{Methods}

\subsubsection{Adsorbent Preparation}

The vermicompost was sieved to obtain particle sizes between 2.38 and $4.76 \mathrm{~mm}$ subsequently, the material was dried at 50 Celsius for 15 hours. The Crushed vermicompost shape can be seen in Figure 1.

\subsubsection{Scanning Electron Microscope Analysis}

Vermicompost surface was analyzed using a Scanning Electron Microscope (SEM). Before analysis, a thin layer of gold covered vermicompost particles using the spray coating. Subsequently, VMC surface was visualized utilizing an electron beam that was accelerated at $20 \mathrm{kV}$.

\subsubsection{Fourier Transform IR Spectroscopy Analysis}

This analysis was performed to identify functional groups on the vermicompost particles using Fourier Transform IR (FTIR) Spectroscopy at a spectral range from 4000 to $600 \mathrm{~cm}^{-1}$. Typically, a powder vermicompost sample was introduced into a diffuse reflectance accessory.

\subsubsection{Mechanical Agitation Time}

Aqueous solutions $(50.00 \mathrm{~mL})$ containing Congo Red (CR) at $40 \mathrm{mg} \cdot \mathrm{L}^{-1}$ or Indigo

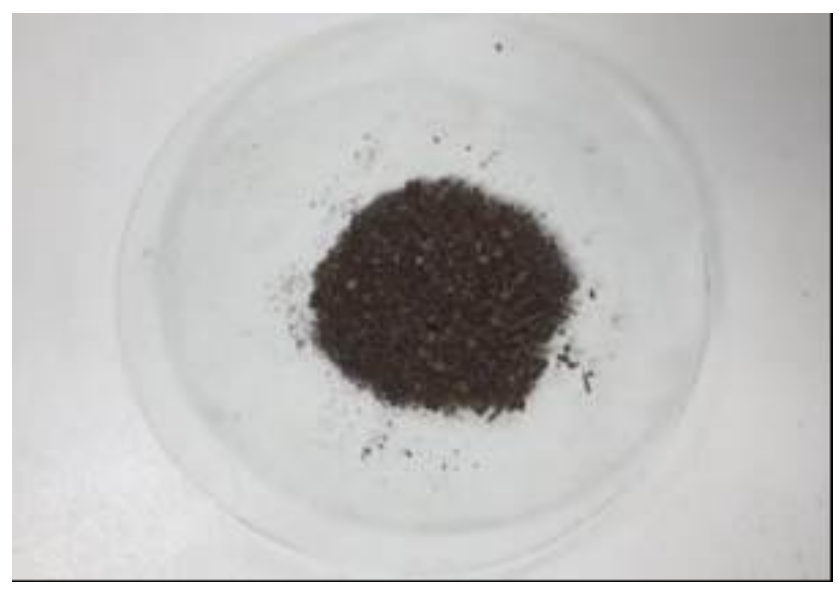

Figure 1. Crushed vermicompost shape. 
Blue (IB) at $1000 \mathrm{mg} \cdot \mathrm{L}^{-1}$ were prepared at $\mathrm{pH}$ 7.0. Subsequently, these solutions were stirred at $1000 \mathrm{rpm}(298.15 \mathrm{~K})$ at different mechanical agitation times (5, $10,15,20,25$, and 30 minutes) with $3.0 \mathrm{~g}$ of vermicompost. The solutions were filtered at vacuum. The absorbance of supernatants was measured at 573 and 500 $\mathrm{nm}$ for IB and CR, respectively. The aim of this test was to evaluate the more adequate mechanical agitation time. These experiments were performed as described by [4] who completed the experiments in triplicate. The percentage of dye retained on the adsorbent at different mechanical agitation times was calculated using Equations (1) and (2).

$$
\begin{gathered}
a d c=i d c-s d c \\
i d c------100 \% \\
\text { adc ------- } x
\end{gathered}
$$

In Equation (1), adc is adsorbed dye concentration, $i d c$ is the initial dye concentration (40 mg. $\mathrm{L}^{-1}$ and $1000 \mathrm{mg} \cdot \mathrm{L}^{-1}$ for $\mathrm{CR}$ and IB, respectively) before mechanical agitation time and filtration, while $s d c$ is the dye concentration $\left(\mathrm{mg} \cdot \mathrm{L}^{-1}\right)$ in the supernatant after filtration. The $s d c$ values were estimated after supernatant quantitative analyses in which dye calibration curves were daily built according to the following concentration ranges: 3 to $50 \mathrm{mg} \cdot \mathrm{L}^{-1}(\mathrm{CR})$ and 10 to $1000 \mathrm{mg} \cdot \mathrm{L}^{-1}$ (IB). In turn, Equation (2) was used to estimate the percentage of dyes (CR or IB) that were adsorbed on vermicompost particles after each mechanical agitation time. After these calculations, a graph relating dye adsorption percentage (\%) and mechanical agitation time was built. These experiments were performed in triplicates and using analytical blanks for each mechanical agitation time. In this case, the analytical blanks consisted of $50.00 \mathrm{~mL}$ ultrapure water and $3.0 \mathrm{~g}$ of vermicompost.

\subsubsection{Vermicompost Mass}

In this experimental part, it was evaluated the influence of vermicompost mass on the adsorption of IB and CR. To perform the experiments, $50.00 \mathrm{~mL}$ of aqueous solutions ( $\mathrm{pH} 7.0)$ containing IB $\left(1000 \mathrm{mg} \cdot \mathrm{L}^{-1}\right)$ or $\mathrm{CR}\left(40 \mathrm{mg} \cdot \mathrm{L}^{-1}\right)$ were stirred $(1000 \mathrm{rpm})\left(25^{\circ} \mathrm{C}\right)$ during 10 and 25 minutes for IB and CR respectively (times selected in the previous step). The solutions containing CR or IB were stirred in the presence of different vermicompost masses $(0.50,1.0,2.0,3.0,4.0$, 5.0 and $6.0 \mathrm{~g}$ ). Subsequently, the solutions were filtered at vacuum for retention of vermicompost particles containing IB or CR. The absorbance of supernatants was measured in triplicate using a spectrophotometer (573 and $500 \mathrm{~nm}$ for IB and $\mathrm{CR}$ respectively) to evaluate the percentage (\%) of these dyes retained on different vermicompost masses. Equations (1) and (2) were also employed to calculate these adsorption percentages, which were plotted against the different vermicompost masses. The percentage of dye retained on different vermicompost masses was also calculated using Equations (1) and (2). These experiments were performed in triplicates and using analytical blanks for each vermicompost mass. In this case, the analytical blanks consisted of $50.00 \mathrm{~mL}$ ultrapure water and different masses of vermicompost. 


\subsubsection{Dye Concentration Influence, Adsorption Isotherms and Derivations of Thermodynamic Parameters}

After determining the more adequate mechanical agitation times and vermicompost masses for both dyes, adsorption isotherms were built using different concentrations of $\mathrm{CR}$ and $\mathrm{IB}$, whose $\mathrm{pH}$ values were adjusted to 7.0. For this purpose, vermicompost particles were mechanically stirred (1000 rpm), at $298.15 \mathrm{~K}$, with $50.00 \mathrm{~mL}$ CR or IB solutions with concentrations ranging from 50 to $500 \mathrm{mg} \cdot \mathrm{L}^{-1}$ and from 50 to $4000 \mathrm{mg} \cdot \mathrm{L}^{-1}$, respectively. For CR solutions, $1 \mathrm{~g}$ of vermicompost and 10 minutes of mechanical agitation time were adopted. In turn, for IB solutions, $3 \mathrm{~g}$ of vermicompost and a mechanical agitation time of 25 minutes were fixed to build adsorption isotherms. Subsequently, the solutions were filtered at vacuum for retention of vermicompost particles containing CR or IB. The supernatant absorbances were measured in a spectrophotometer (573 $\mathrm{nm}$ for IB and $500 \mathrm{~nm}$ for CR) to evaluate the amounts of CR and IB (mg) retained per gram of vermicompost. Once the adsorption isotherms were built for $\mathrm{CR}$ and IB, they were linearized according to the Langmuir Mathematical Model [10] to estimate the following thermodynamic parameters concerning the evaluated adsorptions: maximum adsorption capacity (MAC), Langmuir constant $\left(K_{L}\right)$ that is related to the adsorption energy, variation of Gibbs free energy, and the dimensionless constant $\left(R_{L}\right)$ associated with adsorption processes.

\section{Results and Discussion}

\subsection{Scanning Electron Microscope Analysis}

The Scanning Electron Microscope (SEM) analysis of the vermicompost resulted in a morphological aspect as shown in Figure 2. According to this figure, vermicompost particle surface had heterogeneous and irregular morphology. These morphological characteristics contribute to larger surface area and, consequently, to the adsorption processes [19]. Similar results using SEM for vermicompost were found by [20]. Pereira et al. [10] also verified that the vermicompost, which was efficiently used to adsorb crystal violet and methylene blue dyes, presented very irregular surface.

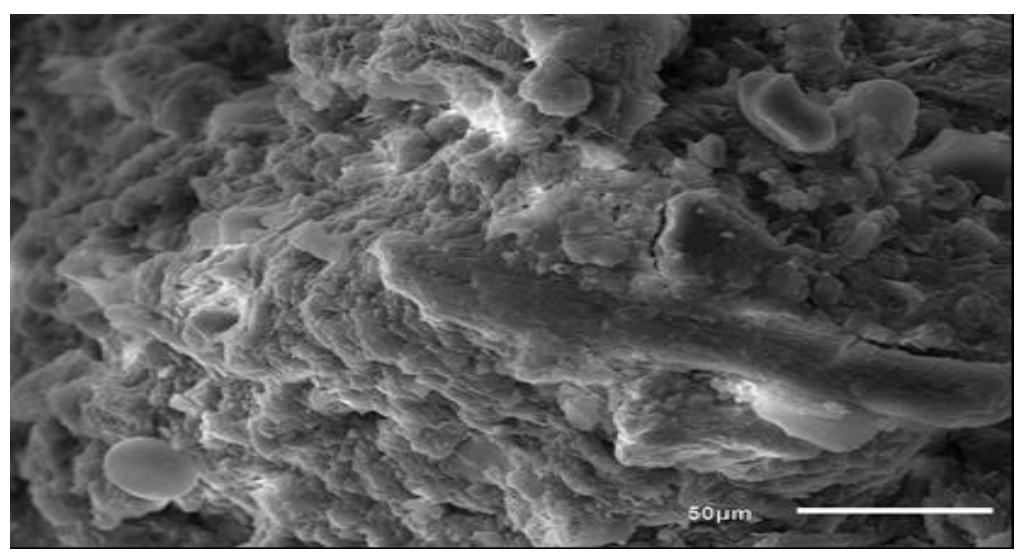

Figure 2. Scanning electron microscopy of the vermicompost with magnifications of $1000 \times$. 


\subsection{Fourier Transform IR Spectroscopy Analysis}

Figure 3 indicates the presence of chemical groups able to adsorb pollutants chemical species as those evaluated in this study [21]. As can be seen, infrared spectrum of vermicompost revealed characteristic bands, as those associated to $\mathrm{N}-\mathrm{H}$ stretching (asymmetrical and symmetrical) at $3694 \mathrm{~cm}^{-1}$ and $3619 \mathrm{~cm}^{-1}$ [20] [22]. Vermicompost spectrum was also characterized by a strong and broad band from $3500-3000 \mathrm{~cm}^{-1}\left(3522 \mathrm{~cm}^{-1}\right.$ and $\left.3436 \mathrm{~cm}^{-1}\right)$ associated to the stretching $v(\mathrm{O}-\mathrm{H})$ of adsorbed water molecules or $\mathrm{H}$-bonded $\mathrm{OH}$ groups, including those presents in acid carboxylic, phenolic, and alcoholic groups [20] [23]. The weak absorption at $2900 \mathrm{~cm}^{-1}$ was related to aliphatic $\mathrm{C}-\mathrm{H}$ stretching, indicating the absence of large amounts of $\mathrm{CH}_{2}$ and $\mathrm{CH}_{3}$ groups [20] [23]. Absorption between $1750-1500 \mathrm{~cm}^{-1}\left(1640 \mathrm{~cm}^{-1}\right)$ was associated to $\mathrm{C}-\mathrm{O}$ and $\mathrm{C}=\mathrm{O}$ stretching bands attributed to the $\mathrm{COOH}$ groups, or to $\mathrm{C}-\mathrm{H}$ of alkene group (Silverstein et al., 1991; Stevenson \& Goh, 1971). Adsorption band at $1400 \mathrm{~cm}^{-1}$ was due to $\mathrm{OH}$ deformation and $\mathrm{C}-\mathrm{O}$ stretching of phenolic $\mathrm{OH}$ groups, and to $\mathrm{C}-\mathrm{H}$ deformation of $\mathrm{CH}_{2}$ and $\mathrm{CH}_{3}$ groups [22] [23]. The broad and weak band at $1200 \mathrm{~cm}^{-1}$ is assigned to $\mathrm{C}-\mathrm{O}$ stretching and $\mathrm{OH}$ deformation of $\mathrm{COOH}$. The strong bands at $1002 \mathrm{~cm}^{-1}$ and $909 \mathrm{~cm}^{-1}$ were associated to the $\mathrm{C}-\mathrm{H}$ stretching of alkene group [22].

Figure 4 reveal that through these characteristics showed in Figure 3 is possible to suppose some interactions between some vermicompost chemical groups and both dyes. The hydrogen bond appears as one of these possible chemical interactions. However, the hydrogen bonds are $\mathrm{pH}$ medium dependent. In this experiment we utilized aqueous solutions dyes with $\mathrm{pH}$ around 7.0.

\subsection{Mechanical Agitation Time}

As can be seen in Figure 5, mechanical agitation times of 10 and 30 minutes were associated with the higher adsorption percentages of Indigo Blue. It is

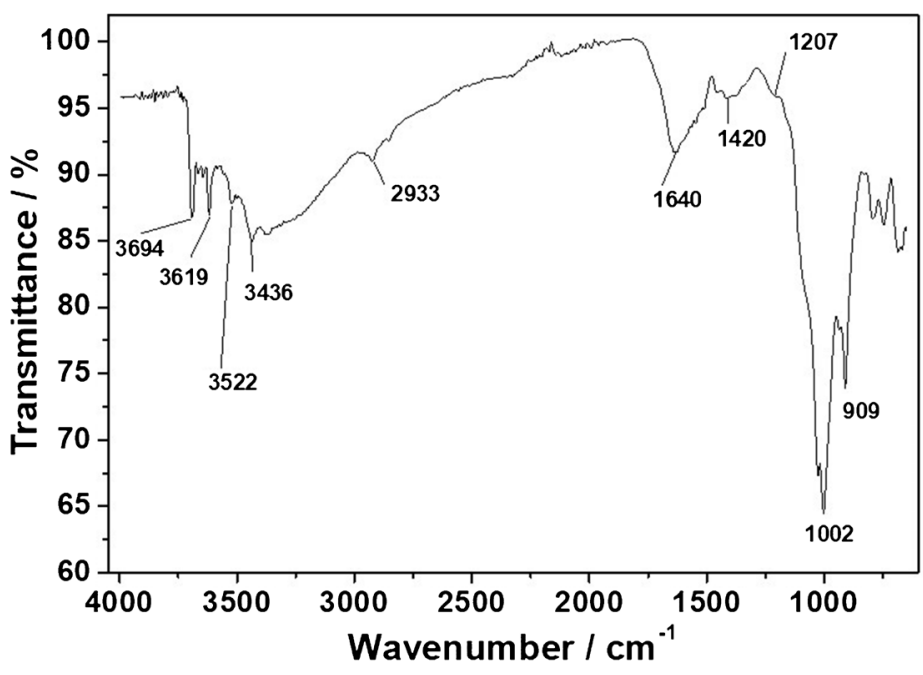

Figure 3. FTIR spectrum of vermicompost. 
(a)
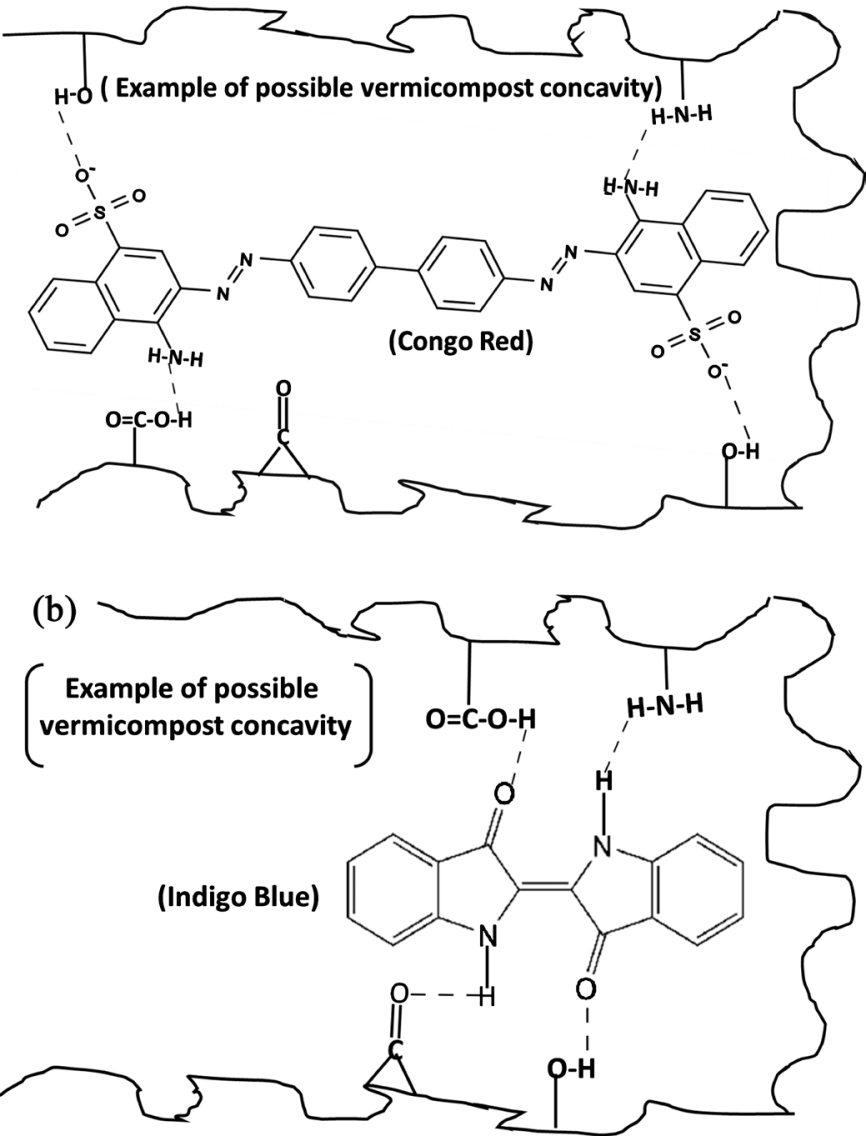

Figure 4. Example of some possible chemical interactions between some chemical groups of vermicompost and Congo Red (a) and Indigo Blue (b).

important to note that there was no significant difference between adsorptions achieved at 10 and 30 minutes. Thus, the mechanical agitation time of $10 \mathrm{mi}-$ nutes was adopted in all adsorption tests involving Indigo Blue. In turn, as indicated in Figure 5, there was a clear favoring of Congo Red adsorption at $25 \mathrm{mi}$ nutes, thus justifying the use of this mechanical agitation time in all adsorption tests with Congo Red. Moreover, it was possible to notice desorption events along the time scale indicated in Figure 5. Raymundo et al. [6] also observed similar results, which were achieved when sugar cane bagasse was used to adsorb Congo Red. Ribeiro et al. [24] also noticed that adsorption of Indigo Blue by $Z i$ ziphus joazeiro peel showed desorption events as mechanical agitation time increased.

\subsection{Vermicompost Mass}

The influence of different vermicompost masses (g) on the adsorption of Congo Red (40 mg. $\left.\mathrm{L}^{-1}\right)$ and Indigo Blue (1000 mg. $\left.\mathrm{L}^{-1}\right)$ is plotted in Figure 6. It was shown that Congo Red adsorption percentage presented small increase from 0.5 to $1.0 \mathrm{~g}$ of vermicompost (approximately $96 \%$ to $100 \%$ ). From $1.0 \mathrm{~g}$, adsorption percentage of Congo Red remained practically constant. Therefore, $1.0 \mathrm{~g}$ of vermicompost was selected for determining the maximum adsorption capacity for 


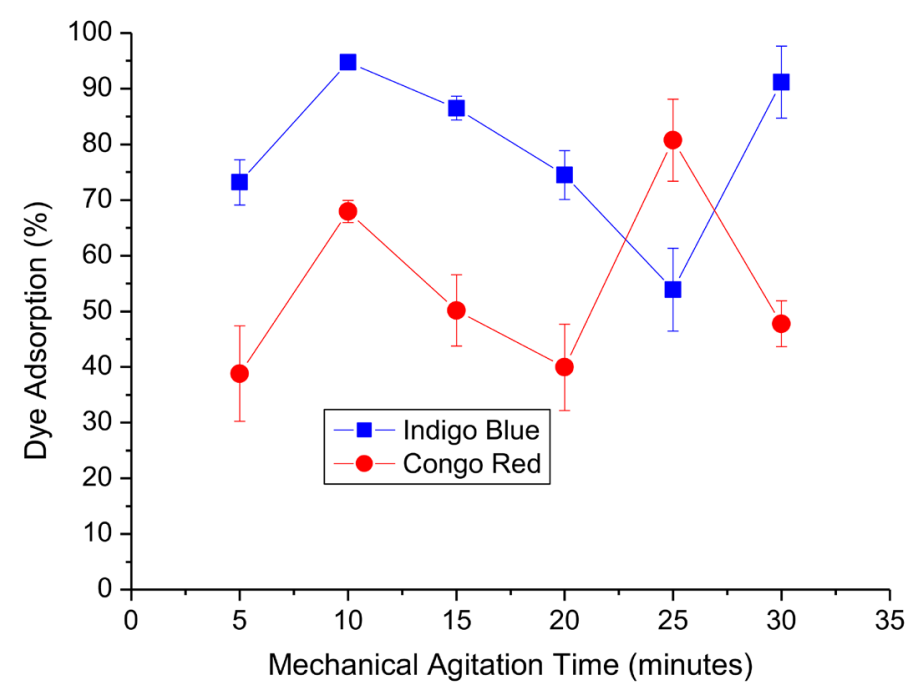

Figure 5. Influence of stirring time on Indigo Blue and Congo Red adsorption (\%).

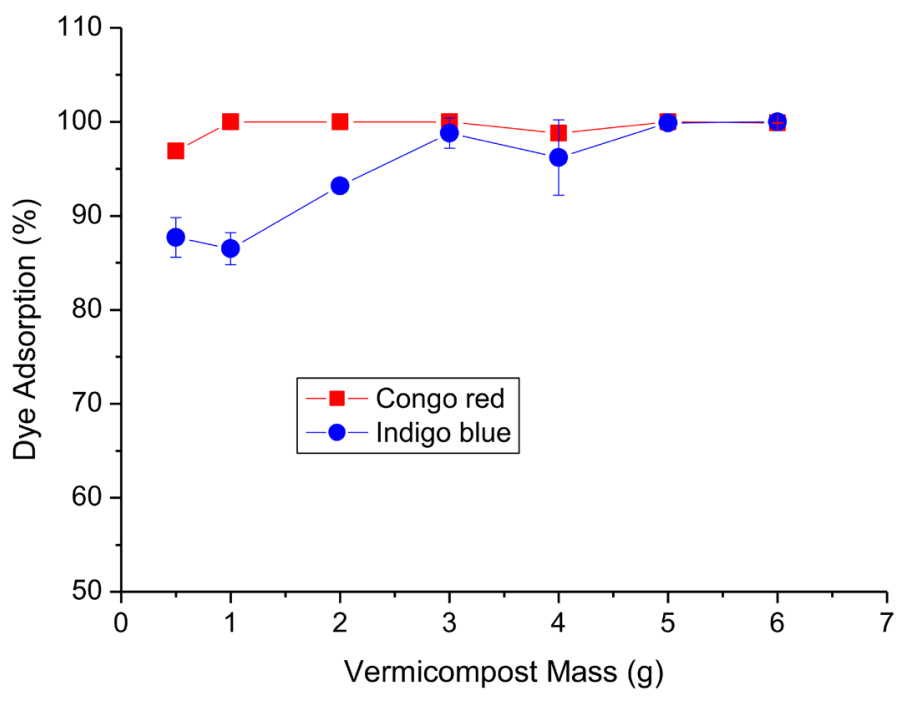

Figure 6. Influence of vermicompost mass on Indigo Blue and Congo Red adsorption (\%).

Congo Red. Indigo Blue adsorption percentage increased when vermicompost mass varied from 0.5 and $3.0 \mathrm{~g}$ (approximately $87.7 \%$ to $99.9 \%$ ), remaining unchanged with the addition of larger masses (Figure 6), thus justifying the use of $3.0 \mathrm{~g}$ of vermicompost along the tests to estimate the maximum adsorption capacity for Indigo Blue. Raymundo et al. [6] utilized sugar-cane bagasse as adsorbent for treating textile wastewater contaminated with Congo Red $(100 \mu \mathrm{M})$ to remove approximately $88 \%$ of this dye using $10 \mathrm{~g}$ of adsorbent. This outcome was considerably different in relation to the vermicompost evaluated in this work (Figure 6). In a work developed by [25], it was determined that $1.5 \mathrm{~g}$ of wood sawdust powder from Corymbia citriodora was able to remove approximately $90 \%$ of Congo Red (25 mg. $\left.\mathrm{L}^{-1}\right)$ from aqueous medium. Ribeiro ${ }^{\mathrm{A}}$ et al. [4] ascertained the liquorice Glycyrrhiza glabra L. root powder as a natural adsorbent to remove textile dyes in water. They demonstrated that $2.0 \mathrm{~g}$ of this adsor- 
bent were able to remove $90 \%$ and $89 \%$ of Congo Red $\left(25 \mathrm{mg} \cdot \mathrm{L}^{-1}\right)$ and Indigo Blue (1000 $\left.\mathrm{mg} \cdot \mathrm{L}^{-1}\right)$, respectively. Ribeiro et al. [24] demonstrated that $1.5 \mathrm{~g}$ of Zizyphus joazeiro Mart peel removed approximately $84 \%$ of Indigo Blue (1000 $\mathrm{mg} \cdot \mathrm{L}^{-1}$ ) from aqueous medium.

\subsection{Dye Concentration Influence, Adsorption Isotherms and Derivations of Thermodynamic Parameters}

The no linearized adsorption isotherms for both dyes (Figure 7 and Figure 8) were built the ration $q\left(\mathrm{mg} \cdot \mathrm{g}^{-1}\right)$ against $C_{e q}\left(\mathrm{mg} \cdot \mathrm{L}^{-1}\right)$, where $q\left(\mathrm{mg} \cdot \mathrm{g}^{-1}\right)$ is the adsorbed amount of dye per gram of vermicompost in each dye concentration evaluated, while $C_{e q}\left(\mathrm{mg} \cdot \mathrm{L}^{-1}\right)$ is the equilibrium concentration of dyes in the supernatants (dye amount no adsorbed by vermicompost). The forms of this isotherms indicate relatively favorable conditions for adsorption [26]. Mathematically, an adsorption isotherm can be treated by different models, but we adopted

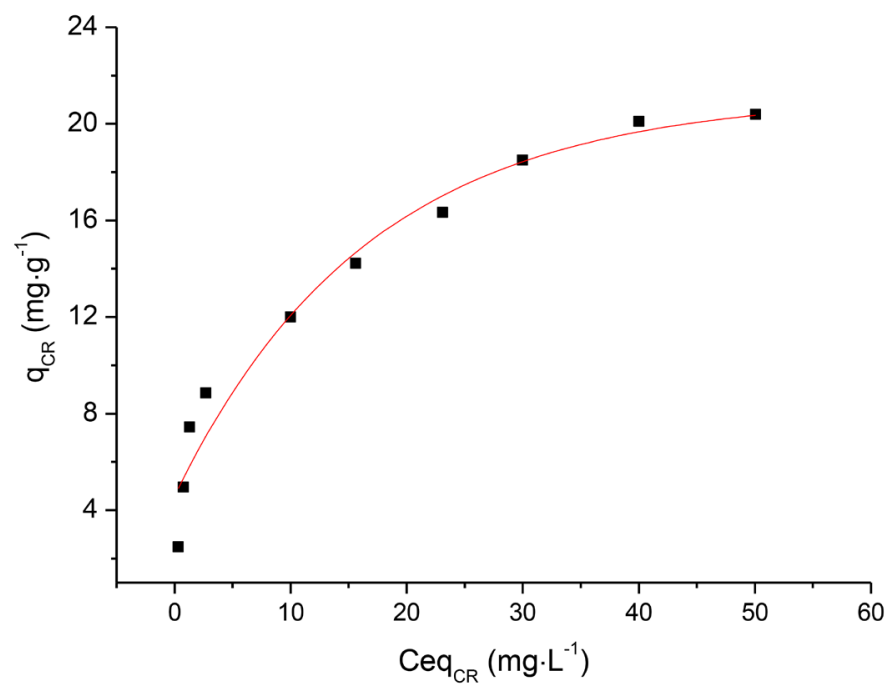

Figure 7. Adsorption isotherm for Congo Red in the presence of vermicompost.

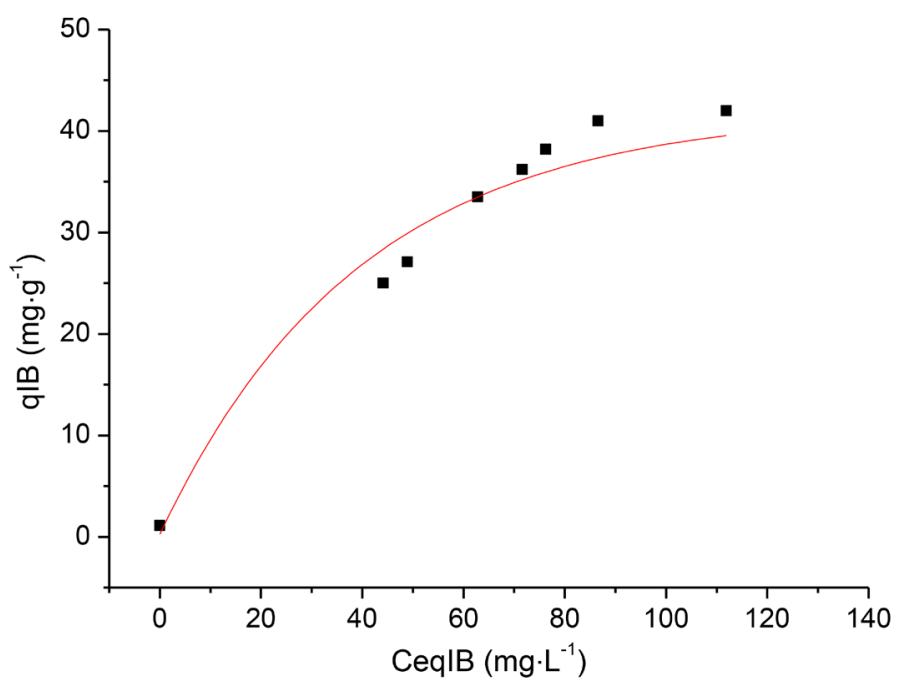

Figure 8. Adsorption isotherm for Indigo Blue in the presence of vermicompost. 
the Langmuir Model [27], which is one the most used models to evaluate the adsorption of pollutants from aqueous media. Langmuir Model considers that adsorption occurs in monolayers, and all adsorption sites have the same energy. Equation (3) is the general equation in which the Langmuir model is based on:

$$
q=K_{L} \cdot M A C \cdot C_{e q} \cdot\left(1+K_{L} \cdot C_{e q}\right)^{-1}
$$

where: $q$ and $C_{e q}$ have the definitions already given, $K_{L}$ is the Langmuir constant $\left(\mathrm{L} \cdot \mathrm{g}^{-1}\right)$, which is related to the adsorption energy, and $M A C$ means maximum adsorption capacity of vermicompost in relation to Congo Red and Indigo Blue, as previously defined. The $M A C$ unit is $\mathrm{mg}^{-\mathrm{g}^{-1}}$ ( $\mathrm{mg}$ of adsorbed dye per gram of vermicompost).

As can be noted, both adsorption isotherms were not linear (Figure 7 and Figure 8), thus presenting a similarity in relation to the results derived from other studies regarding the use of natural adsorbents and synthetic dyes [4] [6] [10] [24] [25].

Maximum adsorption capacity $(M A C)$ and Langmuir constant $\left(K_{L}\right)$ can be estimated after linearizing Equation (3) [plotting the ration $C_{e q} / q\left(\mathrm{~g} \cdot \mathrm{L}^{-1}\right)$ against $\left.C_{e q}\left(\mathrm{mg} \cdot \mathrm{L}^{-1}\right)\right]$, thus resulting in linearized isotherms (Figure 9 and Figure 10) described by Equation (4). In this sense, after analyzing Equation (4), $M A C$ could be defined as the inverse of the angular coefficient. In turn, $K_{L}$ could be estimated as 1 divided by product between $M A C$ and linear coefficient.

$$
C_{e q} / q=\left(K_{L} \cdot M A C\right)^{-1}+(M A C)^{-1} \cdot C_{e q}
$$

When Equation (4) was specifically applied to the data that generated adsorption isotherms showed in Figure 7 and Figure 8, it was possible to obtain Equations (5) and (6), respectively. Equations (5) and (6) represent the lines indicated in Figure 9 and Figure 10, respectively.

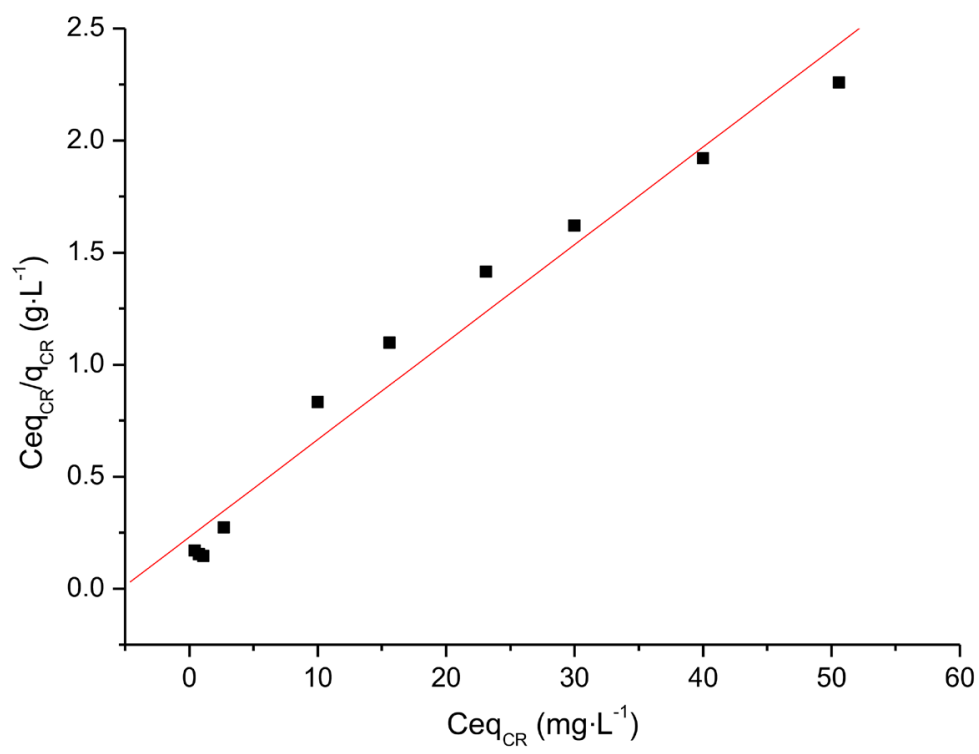

Figure 9. Adsorption isotherm linearization for Congo Red in the presence of vermicompost. 


$$
\begin{gathered}
C_{e q} / q=0.229+0.0430 \cdot C_{e q} \\
C_{e q} / q=0.1610+0.0248 \cdot C_{e q}
\end{gathered}
$$

From the $K_{L}$ values, it was possible to obtain the $\Delta G_{a d s}$ concerning the adsorption processes through Equation (7):

$$
\Delta G_{a d s}=-R T \ln K_{L}
$$

where $\Delta G_{a d s}$ is the variations of Gibbs free energy related to the adsorption processes, $R$ is the universal gas constant $\left(8.314472 \mathrm{~J} \cdot \mathrm{mol}^{-1} \cdot \mathrm{K}^{-1}\right), T$ is the temperature in Kelvin $(298.15 \mathrm{~K})$, and $K_{L}$ is a constant related to the adsorption or binding energy $\left(\mathrm{L} \cdot \mathrm{mol}^{-1}\right)$, between vermicompost and dyes. The values of $K_{L}$ were originally calculated in $\mathrm{L} \cdot \mathrm{g}^{-1}$, but these values were subsequently converted to L-mol ${ }^{-1}$. Table 1 lists all thermodynamic parameters concerning the adsorption of Congo Red and Indigo Blue on vermicompost. As can be seen in Table 1, the $R^{2}$ (Determination Coefficient) values for Equations (5) and (6) highlighted good adjustments of the Langmuir Model in relation to the evaluated adsorption results. The values of $\Delta G_{a d s}$ indicate the nature of adsorption. Thus, $\Delta G_{a d s}<-200$ $\mathrm{kJ} \cdot \mathrm{mol}^{-1}$ reveals chemical adsorption with low reversibility degree [28]. In this context, all adsorptions that were evaluated in this study could be classified as

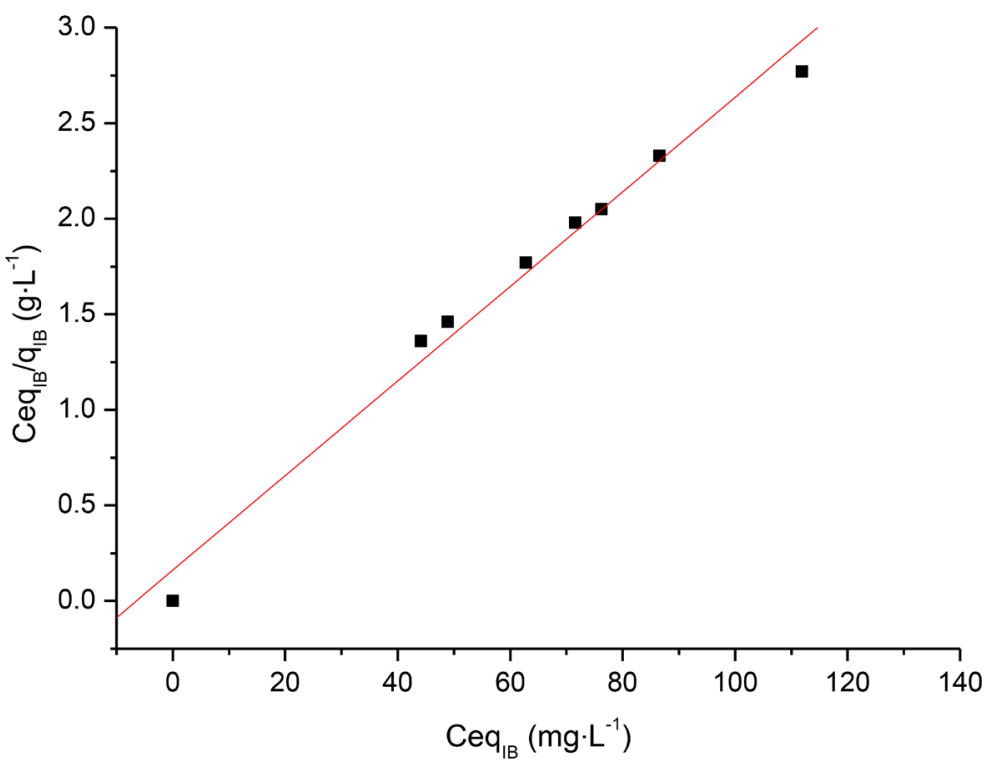

Figure 10. Adsorption isotherm linearization for IB in the presence of vermicompost.

Table 1. Physicochemical parameters concerning the adsorption of Congo Red and Indigo Blue on vermicompost.

\begin{tabular}{ccc}
\hline Physicochemical parameters & Congo Red & Indigo Blue \\
\hline $\mathrm{R}^{2}$ & 0.9841 & 0.9919 \\
$\mathrm{MAC}\left(\mathrm{mg} \cdot \mathrm{g}^{-1}\right)$ & 23.25 & 40.39 \\
$K_{L}\left(\mathrm{~L} \cdot \mathrm{mg}^{-1}\right)$ & 0.19 & 0.15 \\
$\Delta G\left(\mathrm{KJ} \cdot \mathrm{mol}^{-1}\right)$ & -29.24 & -26.22 \\
\hline
\end{tabular}


physical adsorption, in which it is observed weaker interactions between dyes and vermicompost. Therefore, it can be said that the chemical interactions shown in Figure 4 are not dominant, occurring discreetly in a much lesser degree than before mentioned.

These discrete values of $\Delta G_{a d s}$ are consistent with the structures of the evaluated dyes (Congo Red and Indigo Blue), which have bulky molecular structures with high electronic density. Both features are responsible for steric impediments and electrostatic repulsions, thus avoiding effective accommodation of the dyes on vermicompost particles. Based on the $K_{L}$ values, which are related to the adsorption energy, it was possible to identify similar affinities of both dyes in relation to the adsorption sites. Ultimately, this outcome reveals that both molecular structures, although remarkably different, presented a set of common characteristics capable of decreasing adsorption strength. Despite low adsorption strength, which are related to the relatively small $K_{L}$ values, reasonable values of $M A C$ were achieved for both dyes, mainly for Indigo Blue. This finding means that despite the low adsorption energy, appreciable amounts of Congo Red and Indigo Blue could be retained per gram of vermicompost. The comparison between the $M A C$ values obtained in this work with the values shown in Table 2 reveals that the adsorption of CR and IB by natural adsorbents is many varied [4] [6] [17] [24] [25] [29]-[35]. For CR, values vary between $0.52 \mathrm{mg} \cdot \mathrm{g}^{-1}$ [25] and $751 \mathrm{mg} \cdot \mathrm{g}^{-1}$ [29]. While for IB all values, except one [4], have $M A C$ around 50 $\mathrm{mg}^{-1}$ [17] [24] [30]. Making a comparative critical analysis, the values revealed in this work are satisfactory. In addition, the vermicompost used in this work is totally natural. No chemical modifications were made to it.

Table 2. $M A C$ values for adsorption of $\mathrm{CR}$ and IB by different adsorbents.

\begin{tabular}{cccc}
\hline Adsorbent & Pollutant & $\begin{array}{c}M A C \text { values } \\
\left(\mathbf{m g} \cdot \mathbf{g}^{-1}\right)\end{array}$ & References \\
\hline Liquorice root powder & Congo Red & 0.77 & {$[4]$} \\
Liquorice root powder & Indigo Blue & 1.70 & {$[4]$} \\
Sugarcane bagasse & Congo Red & 4.43 & {$[6]$} \\
Sodium carboxymethyl cellulose and chitosan & Indigo Blue & 50.00 & {$[17]$} \\
Zizyphusjoazeiro peel & Indigo Blue & 50.00 & {$[24]$} \\
Wood sawdust powder & Congo Red & 0.52 & {$[25]$} \\
Corncob-to-xylose residue (CCXR) & Congo Red & 751.00 & {$[29]$} \\
Natural clay & Indigo Blue & 57.00 & {$[30]$} \\
Activated carbon & Indigo Blue & 53.00 & {$[30]$} \\
Algerian kaolin & Congo Red & 6.53 & {$[31]$} \\
Natural zeolites modified with N,N-dimethyl & Congo Red & 69.94 & {$[32]$} \\
dehydroabietylamine oxide & Congo Red & 128.94 & {$[33]$} \\
Coconut residual fiber & Congo Red & 4.05 & {$[34]$} \\
Red mud & Congo Red & 319.08 & {$[35]$} \\
\hline Polysaccharide of Carica papaya seeds & & &
\end{tabular}


The dimensionless constant $\left(R_{L}\right)$ is another thermodynamic parameter to favoring the adsorption process. In this case, $0<R_{L} \leq 1$ indicates favorable adsorptions, while $R_{L}>1$ can be attributed to unfavorable adsorptions (Esmaeili and Beni 2015). $R_{L}$ is calculated by means of Equation (8), where $M A C$ is the maximum adsorption capacity and $C_{0}$ is the highest dye concentration (500 and 4000 $\mathrm{mg} \cdot \mathrm{L}^{-1}$ for Congo Red and Indigo Blue, respectively) used for building adsorption isotherm.

$$
R_{L}=1 /\left(1+M A C \cdot C_{0}\right)
$$

After substituting $M A C$ and $C_{0}$ values in Equation (8), it was possible to achieve the following values of $R_{L}: 0.000086$ and 0.0000062 for Congo Red and Indigo Blue, respectively. In this sense, adsorptions of Congo Red and Indigo Blue were favorable.

\section{Conclusion}

The surface and chemical groups analysis, besides tests of adsorbent mass, stirring time, determination of physicochemical parameters, and $M A C$ values reveal that the vermicompost is an efficient remover of CR and IB dyes from the aqueous medium. Studies using other dyes can transform this material into a filter component for cleaning industrial effluents.

\section{Conflicts of Interest}

The authors declare no conflicts of interest regarding the publication of this paper.

\section{References}

[1] Maghri, I., Amegrissi, F., Mohamed, E., Kenz, A., Tanane, O., Mohamed, T. and Salouhi, M. (2012) Comparison of Adsorption of Dye onto Low-Cost Adsorbents. Global Journal of Science Frontier Research Chemistry, 12, 7-12.

[2] Kebaili, M., Djellali, S., Radjai, M., Drouiche, N. and Lounici, H. (2018) Valorization of Orange Industry Residues to Form a Natural Coagulant and Adsorbent. Journal of Industrial and Engineering Chemistry, 64, 292-299. https://doi.org/10.1016/j.jiec.2018.03.027

[3] Sun, Q., Saratale, R.G., Saratale, G.D. and Kim D.-S. (2018) Pristine and Modified Radix Angelicae dahuricae (Baizhi) Residue for the Adsorption of Methylene Blue from Aqueous Solution: A Comparative Study. Journal of Molecular Liquids, 265, 36-45. https://doi.org/10.1016/j.molliq.2018.05.108

[4] Ribeiro, A.V.F.N., da Silva, A.R., dos Silvares, P.H.S., de Loiola, A.O., Monteiro, F.C., de Pereira, M.G. and Ribeiro, J.N. (2018) Evaluation of Liquorice Glycyrrhiza glabra L. Root Powder as a New Adsorbent in the Removal of Textile Dyes in Aqueous Medium. International Journal of Advanced Research, 6, 278-290. https://doi.org/10.21474/IJAR01/7520

[5] Munagapati, V.S., Yarramuthi, V., Kim, Y., Lee, K.M. and Kim, D.-S. (2018) Removal of Anionic Dyes (Reactive Black 5 and Congo Red) from Aqueous Solutions Using Banana Peel Powder as an Adsorbent. Ecotoxicology and Environmental Safety, 148, 601-607. https://doi.org/10.1016/j.ecoenv.2017.10.075 
[6] Raymundo, A.S., Zanarotto, R., Belisário, M., de Pereira, M.G., Ribeiro, J.N. and Ribeiro, A.V.F.N. (2010) Evaluation of Sugar-Cane Bagasse as Bioadsorbent in the Textile Wastewater Treatment Contaminated with Carcinogenic Congo Red Dye. Brazilian Archives of Biology and Technology, 53, 931-938. https://doi.org/10.1590/S1516-89132010000400023

[7] Wang, Q., Wang, Y. and Chen, L. (2019) A Green Composite Hydrogel Based on Cellulose and Clay as Efficient Absorbent of Colored Organic Effluent. Carbohydrate Polymers, 210, 314-321.

https://doi.org/10.1016/j.carbpol.2019.01.080

[8] Kubra, K.T., Salman, S. and Hasan, N. (2021) Enhanced Toxic Dye Removal from Wastewater Using Biodegradable Polymeric Natural Adsorbent. Journal of Molecular Liquids, 328, Article ID: 115468. https://doi.org/10.1016/j.molliq.2021.115468

[9] Jawad, A.H. and Abdulhammed, A.S. (2020) Mesoporous Iraqi Red Kaolin Clay as an Efficient Adsorbent for Methylene Blue Dye: Adsorption Kinetic, Isotherm and Mechanism Study. Surface and Interfaces, 18, Article ID: 100422.

https://doi.org/10.1016/j.surfin.2019.100422

[10] De Pereira, M.G., Korn, M., Santos, B.B. and Ramos, M.G. (2009) Vermicompost for Tinted Organic Cationic Dyes Retention. Water, Air, and Soil Pollution, 200, 227-235. https://doi.org/10.1007/s11270-008-9906-6

[11] Ciğeroğlu, Z. and Yildirir, E. (2020) Vermicompost as a Potential Adsorbent for the Adsorption of Methylene Blue Dye from Aqueous Solutions. Journal of the Turkish Chemical Society Section A: Chemistry, 7, 893-902. https://doi.org/10.18596/jotcsa.784357

[12] Paradelo, R., Vecino, X., Moldes, A.B. and Barral, M.T. (2019) Potential Use of Composts and Vermicomposts as Low-Cost Adsorbents for Dye Removal: An Overlooked Application. Environmental Science and Pollution Research, 26, 21085-21097. https://doi.org/10.1007/s11356-019-05462-x

[13] Fernandez-Bayo, J.D., Romero, E., Schnitzler, F. and Burauel, P. (2008) Assessment of Pesticide Availability in Soil Fractions after the Incorporation of Winery-Distillery Vermicomposts. Environmental Pollution, 154, 330-337. https://doi.org/10.1016/j.envpol.2007.10.002

[14] Matos, G.D. and Arruda, M.A.Z. (2003) Vermicompost as Natural Adsorbent for Removing Metal Ions from Laboratory Effluents. Process Biochemistry, 39, 81-88. https://doi.org/10.1016/S0032-9592(02)00315-1

[15] He, X., Zhang, Y., Shen, M., Tian, Y., Zheng, K. and Zeng, G. (2017) Vermicompost as a Natural Adsorbent: Evaluation of Simultaneous Metals ( $\mathrm{Pb}, \mathrm{Cd})$ and Tetracycline Adsorption by Sewage Sludge-Derived Vermicompost. Environmental Science and Pollution Research, 24, 8375-8384. https://doi.org/10.1007/s11356-017-8529-0

[16] Bates, L. (2016) Humic Substances and Natural Organic Matter. Nova Science Publishers, New York.

[17] Zhu, X., Bao, L., Wei, Y., Ma, J. and Kong, Y. (2016) Removal of Toxic Indigo Blue with Integrated Biomaterials of Sodium Carboxymethyl Cellulose and Chitosan. International Journal of Biological Macromolecules, 91, 409-415.

https://doi.org/10.1016/j.ijbiomac.2016.05.097

[18] Chatterjee, S., Chatterjee, S., Chatterjee, B.P. and Guha, A.K. (2007) Adsorptive Removal of Congo Red, a Carcinogenic Textile Dye by Chitosan Hydrobeads: Binding Mechanism, Equilibrium and Kinetics. Colloids and Surfaces A: Physicochemical and Engineering Aspects, 299, 146-152. https://doi.org/10.1016/j.colsurfa.2006.11.036 
[19] Landgraf, M.D., da Silva, S.C. and de Rezende, M.O.O. (1998) Mechanism of Metribuzin Herbicide Sorption by Humic Acid Samples from Peat Vermicompost. Analytica Chimica Acta, 368, 155-164. https://doi.org/10.1016/S0003-2670(98)00049-X

[20] Pereira, M.G. and Arruda, M.A.Z. (2003) Vermicompost as a Natural Adsorbent Material: Characterization and Potentialities for Cadmium Adsorption, Journal of the Brazilian Chemical Society, 14, 39-47. https://doi.org/10.1590/S0103-50532003000100007

[21] Yurtsever, M. and Şengil, L.A. (2009) Biosorption of Pb(II) Ions by Modified Quebracho Tannin Resin. Journal of Hazardous Materials, 163, 58-64. https://doi.org/10.1016/j.jhazmat.2008.06.077

[22] Silverstein, R.M., Bassler, G.C. and Morrill T.C. (1991) Spectrometric Identification of Organic Compounds. 5th Edition, John Wiley \& Sons, Hoboken.

[23] Stevenson, F.J. and Goh, K.M. (1971) Infrared Spectra of Humic Acids and Related Substances. Geochimica et Cosmochimica Acta, 35, 471-483.

https://doi.org/10.1016/0016-7037(71)90044-5

[24] Ribeiro, J.N., Ribeiro, A.V.F.N., Monteiro, F.C., Licinio, M.V.V.J. and Pereira, M.G. (2019) Study of the Ziziphus Joazeiro Peel for Indigo Blue Adsorption. International Journal of Advanced Research, 7, 171-178. https://doi.org/10.21474/IJAR01/8617

[25] Ribeiro, A.V.F.N., Silva, A.R., Pereira, M.G., Licinio M.V.V.J. and Ribeiro, J.N. (2018) Wood Sawdust Powder from Corymbia citriodora to Congo Red Toxic Dye Adsorption. Indian Journal of Applied Research, 8, 449-451.

[26] Kaushal, A. and Sing, S.K. (2017) Critical Analysis of Adsorption Data Statistically. Applied Water Science, 7, 3191-3196. https://doi.org/10.1007/s13201-016-0466-4

[27] Langmuir, I. (1918) The Adsorption of Gases in Plane Surface of Glass, Mica, and Platinum. Journal of the American Chemical Society, 40, 1361-1403.

https://doi.org/10.1021/ja02242a004

[28] Bayramoglu, G., Altintas, B. and Yakup A.M. (2009) Adsorption Kinetics and Thermodynamic Parameters of Cationic Dyes from Aqueous Solutions by Using a New Strong Cation-Exchange Resin. Chemical Engineering Journal, 152, 339-346. https://doi.org/10.1016/j.cej.2009.04.051

[29] Yu, Y., Wan, Y., Shang, H., Wang, B., Zhang, P. and Feng, Y. (2019) Corncob to Xylose Residue (CCXR) Derived Porous Biochar as an Excellent Adsorbent to Remove Organic Dyes from Wastewater. Surface and Interface Analysis, 51, 234-245. https://doi.org/10.1002/sia.6575

[30] Mahzoura, M., Tahri, N., Daramola, N.O., Duplay, J., Schafer, G. and Ben Amar, R. (2019) Comparative Investigation of Indigo Blue Dye Removal Efficiency of Activated Carbon and Natural Clay in Adsorption/Ultrafiltration System. Desalination and Water Treatment, 164, 326-328. https://doi.org/10.5004/dwt.2019.24361

[31] Meroufel, B., Benali, O., Beniyahia, M., Bemmoussa, Y. and Zenasni, M.A. (2013) Adsorptive Removal of Anionic Dye from Aqueous Solutions by Algerian Kaolin: Characteristics, Isotherm, Kinetic and Thermodynamic Studies. Journal of Materials and Environmental Science, 4, 482-491.

[32] Liu, S., Ding, Y., Li, P., Diao, K., Tan, X., Lei, F., Zhan, Y., Li, Q., Huang, B. and Huang, Z. (2014) Adsorption of the Anionic Dye Congo Red from Aqueous Solution onto Natural Zeolites Modified with $N, N$-dimethyl Dehydroabietylamine Oxide. Chemical Engineering Journal, 248, 135-144. https://doi.org/10.1016/j.cej.2014.03.026

[33] Rani, K.C., Naik, A., Chaurasiya, R.S. and Raghavarao, K.S.M.S. (2017) Removal of 
Toxic Congo Red Dye from Water Employing Low-Cost Coconut Residual Fiber. Water Science and Technology, 75, 2225-2236. https://doi.org/10.2166/wst.2017.109

[34] Namasivayam, C. and Arasi, D.J.S.E. (1997) Removal of Congo Red from Wastewater by Adsorption onto Waste Red Mud. Chemosphere, 34, 401-417. https://doi.org/10.1016/S0045-6535(96)00385-2

[35] Fatombi, J.K., Osseni, S.A., Idohou, E.A., Agani, I., Neumeyer, D., Verelst, M., Mauricot, R. and Aminou, T. (2019) Characterization and Application of Alkali-Soluble Polysaccharide of Carica papaya Seeds for Removal of Indigo Carmine and Congo Red Dyes from Single and Binary Solutions. Journal of Environmental Chemical Engineering, 7, Article ID: 103343.

https://doi.org/10.1016/j.jece.2019.103343 